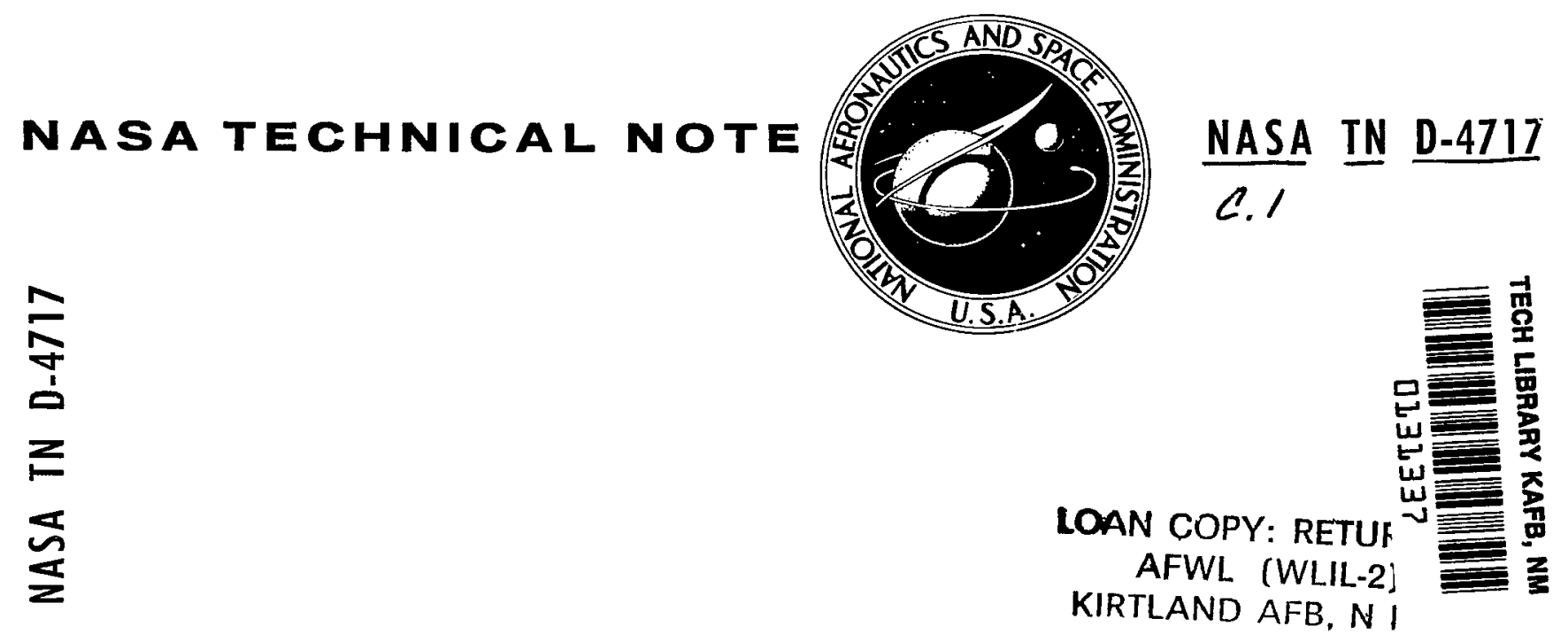

\title{
A NUMERICAL PROCEDURE FOR CALCULATING STRESS AND DEFORMATION NEAR A SLIT IN A THREE-DIMENSIONAL ELASTIC-PLASTIC SOLID
}

by David J. Ayres

Lewis Research Center

Cleveland, Obio

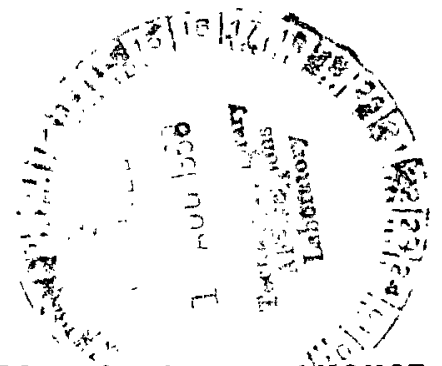

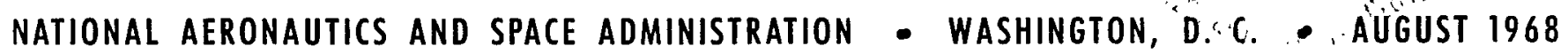




\section{A NUMERICAL PROCEDURE FOR CALCULATING STRESS AND DEFORMATION NEAR A SLIT IN A THREE-DIMENSIONAL ELASTIC-PLASTIC SOLID}

By David J. Ayres

Lewis Research Center Cleveland, Ohio

\section{NATIONAL AERONAUTICS AND SPACE ADMINISTRATION}




\section{ABSTRACT}

A finite difference procedure for the computation of the stress in a three-dimensional solid is presented. This iterative technique, based on Newton's method for determining the roots of a system of polynomials, is applicable to both linear and nonlinear problems. The sample problems that are treated are the analysis of a plate in plane strain with a slit at its center, the analysis of a thick plate with a rectangular slit through its thickness, and the analysis of a thick plate containing a semielliptical slit which extends only halfway through its thickness. The loading condition in all sample problems is uniaxial tension normal to the slit. 


\title{
A NUMERICAL PROCEDURE FOR CALCULATING STRESS AND DEFORMATION
}

\section{NEAR A SLIT IN A THREE-DIMENSIONAL ELASTIC-PLASTIC SOLID}

\author{
by David J. Ayres
}

\author{
Lewis Research Center
}

\section{SUMMARY}

A finite difference procedure for the computation of stress and deformation in a three-dimensional elastic-plastic solid is presented. This iterative technique, based on Newton's method for determining the roots of a system of polynomials, is applicable to both linear and nonlinear problems. The procedure requires a minimum of computer storage capability and moderate computer running time.

Three sample stress-concentration problems are treated. The first problem is the analysis of a plate in plane strain with a slit at its center, the second is the analysis of a thick plate with a rectangular slit through its thickness, and the last is the analysis of a thick plate containing a semielliptical slit which extends only halfway through the thickness. The loading condition in all sample problems is uniaxial tension normal to the slit.

\section{INTRODUCTION}

Numerical methods which involve the solution of large systems of simultaneous equations have long been applied to two-dimensional problems in solid mechanics. The relaxation technique of Southwell (ref. 1), the matrix displacement methods of Clough (ref. 2) and Argyris (ref. 3), the discrete model of Ang and Harper (ref. 4), and the method of successive elastic solutions of Mendelson (ref. 5) are some of the procedures that have been successfully applied to two-dimensional elastic-plastic problems.

The matrix displacement method is the only numerical procedure that has been successfully applied to three-dimensional problems (ref. 3). The computer storage and running time requirements, however, are great because of the large number of simultaneous equations to be solved. In particular, the accurate determination of the stress near a slit in a three-dimensional elastic-plastic body requires the solution of so many 
simultaneous equations that the running time on present day computers discourages the use of this method.

In order to efficiently solve three-dimensional problems using computers that are available today, a new procedure is required. This procedure must permit the solution of thousands of simultaneous equations fairly rapidly. It must be sufficiently general so that problems concerning many different types of materials can be solved, and it must be sufficiently accurate to give a useful approximation of the stress close to a slit. This report presents such a numerical procedure.

The procedure presented herein is an extension of the general method for computing stress and deformation developed in reference 6 and was inspired by the iterative method of Ang and Harper (ref. 4). For this procedure the partial differential equations of equilibrium of the solid are written as finite difference equations in terms of the displacement of points of the solid. These equations are solved iteratively by a relaxation technique. This relaxation converges for linear and nonlinear equations in three dimensions if a reasonable first approximation to the displacement of the solid is assumed. The stress in the body is computed from the resulting displacements.

In this report, the solid is assumed to be elastic and perfectly plastic, obeying Hooke's Law, the Mises-Hencky yield condition, and the Prandtl-Reuss flow rule. The procedure is illustrated by three examples of a slit in an elastic-plastic plate. The first example is a slit in plane strain, the second is a thick plate with a rectangular slit through the thickness, and the third is a thick plate with a semielliptical slit only partially through its thickness.

\section{SYMBOLS}

In this report the conventional summation notation is employed. For example,

$$
a_{i i}=a_{11}+a_{22}+a_{33}
$$

where the range of the index is three unless otherwise indicated. The following symbols are used:

b width of plate

c half length of slit in the $\mathrm{X}_{1}$ direction

d small increase in a displacement component

DU difference between trial value of displacement component and value which would cause zero residual 


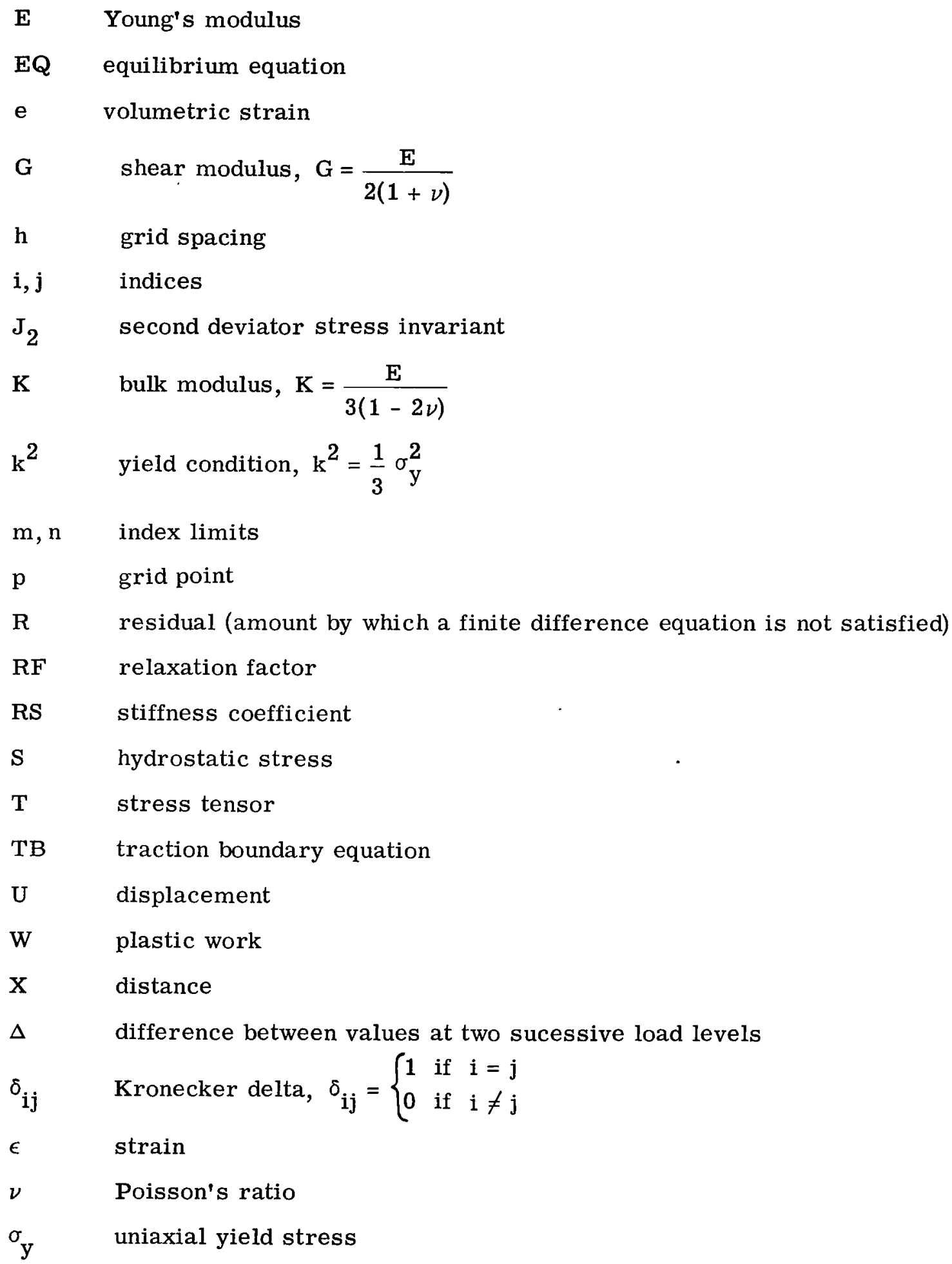




\section{BASIC EQUATIONS}

Every point in a solid body must satisfy the equations of equilibrium. For a stationary body with no body forces acting these equations can be written in Cartesian coordinates as follows:

$$
\frac{\partial T_{i j}}{\partial X_{j}}=0 \quad\left\{\begin{array}{l}
j=1,2,3 \\
i=1,2,3
\end{array}\right.
$$

where the $T_{i j}$ are the components of the stress tensor $T$ in the body at the point with coordinates $\left(\mathrm{X}_{1}, \mathrm{X}_{2}, \mathrm{X}_{3}\right)$.

The behavior of each material can be described by a constitutive equation. An elastic, perfectly plastic material is described by the combination of Hooke's Law, the Mises-Hencky yield condition, and the Prandtl-Reuss flow rule. In Cartesian coordinates the constitutive equation derived in reference 4 can be written in incremental form as

$$
\Delta T_{i j}=2 G\left[\Delta \epsilon_{i j}-\delta_{i j} \Delta e-\frac{\Delta W}{2 k^{2}}\left(T_{i j}-\delta_{i j} S\right)\right]+3 K \delta_{i j} \Delta e
$$

where

$$
\begin{aligned}
& \mathrm{e}=\frac{\epsilon_{\mathrm{ii}}}{3} \quad \mathrm{~S}=\frac{\mathrm{T}_{\mathrm{ii}}}{3} \\
& \Delta W=\left\{\begin{array}{l}
\left(T_{i j}-\delta_{i j} S\right)\left(\Delta \epsilon_{i j}-\delta_{i j} \Delta e\right) \quad \text { if } J_{2}=k^{2} \\
0 \quad \text { if } J_{2}<k^{2}
\end{array}\right. \\
& J_{2}=\frac{1}{2}\left(T_{i j}-\delta_{i j} S\right)\left(T_{i j}-\delta_{i j} S\right) \\
& \epsilon_{i j}=\frac{1}{2}\left(\frac{\partial U_{i}}{\partial X_{j}}+\frac{\partial U_{j}}{\partial X_{i}}\right)
\end{aligned}
$$

The $T_{i j}$ are known from the previous load increment, and $U_{i}$ are the components of the 
displacement of the body at the point $\left(\mathrm{x}_{1}, \mathrm{x}_{2}, \mathrm{x}_{3}\right)$. On the boundary of the body, either traction or displacement must be assigned.

If the stress tensor $T$ satisfies equation (1) for a particular boundary condition and constitutive equation and the boundary condition is altered so that the stress changes by $\Delta \mathrm{T}$, from equation (1) the $\Delta \mathrm{T}_{\mathrm{ij}}$ must satisfy the equation

$$
\frac{\partial \Delta \mathbf{T}_{\mathbf{i j}}}{\partial \mathbf{X}_{\mathbf{j}}}=\mathbf{0}
$$

Substituting equations (2) and (3) into equation (4) results in a set of three simultaneous partial differential equations in terms of the three unknown displacement components and the known stresses and displacements from the previous load increment. These equations are solved by a finite difference technique. Certain points in the body are designated as grid points, and the displacement $U$ of the body is defined at these points. When the finite difference approximations to the derivatives of $U$ are substituted into equation (4), written at each grid point in the body, the system of partial differential equations reduces to a large number of simultaneous polynomial equations which are written symbolically as

$$
\mathrm{EQ}_{\mathrm{ip}}\left(\Delta \mathrm{U}_{1}, \Delta \mathrm{U}_{2}, \Delta \mathrm{U}_{3}\right)=0 \quad\left\{\begin{array}{l}
\mathrm{i}=1,2,3 \\
\mathrm{p}=1, \ldots, \mathrm{n}
\end{array}\right.
$$

where $\mathrm{n}$ is the number of interior grid points.

The constitutive equation must be satisfied at every boundary grid point. When traction is prescribed in a particular direction at a boundary point, the constitutive equation is used to determine the displacement in that direction. When the finite difference approximations to the derivatives of $U$ are substituted into equation (2), the traction boundary condition is written in symbolic form as

$$
\mathrm{TB}_{\mathrm{ip}}\left(\Delta \mathrm{U}_{1}, \Delta \mathrm{U}_{2}, \Delta \mathrm{U}_{3}\right)=0 \quad\left\{\begin{array}{l}
\mathrm{i}=1,2,3 \\
\mathrm{p}=1, \ldots ., \mathrm{m}
\end{array}\right.
$$

where $\mathrm{m}$ is the number of boundary points where traction is prescribed. The displacement $U$ at each grid point is determined by the simultaneous solution of equations (5) and (6). A more detailed derivation of equation (5) and (6) is presented in appendix A. 


\section{NUMERICAL PROCEDURE}

The numerical procedure for the solution of the finite difference equations (eqs. (5) and (6)) is briefly stated as follows:

(1) Designate certain points of the body as grid points. Choose a set of values for the displacement $U$ that approximates the effect of the applied load at all these points.

(2) Starting at a convenient point (preferably near the slit), substitute the displacement components into the equilibrium equation (eq. (5)) or the boundary condition (eq. (6)) for a particular direction $i$. Then calculate the residual $R_{i, 1}$, the amount by which the equation is not satisfied.

(3) Alter the displacement component in the $i$ direction $U_{i}$ by a small arbitrary amount $d$. Compute the residual $R_{i, 2}$ when the altered displacement is used.

(4) Calculate a new value $U_{i \text { (new) }}$ that causes the residual for this equation to be less than $R_{i, 1}$ found in step 2 . This value is calculated by the extrapolation illustrated in figure 1 to be

$$
U_{i(\text { new })}=U_{i \text { (guess) }}+\frac{D U}{R F}=U_{i \text { (guess) }}-\frac{R_{i, 1}}{\frac{\left(R_{i, 2}-R_{i, 1}\right) R F}{d}}
$$

(The selection of the relaxation factor RF is discussed for each example.)

(5) Repeat this procedure (steps 2 to 4 ) for each direction $i$ at each point $p$ in the body.

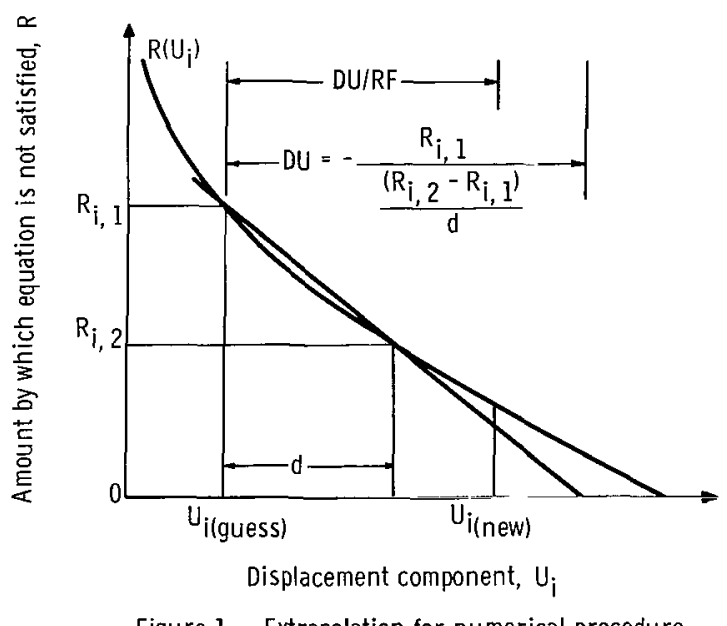

Figure 1. - Extrapolation for numerical procedure. 
(6) Repeat the complete procedure (steps 2 to 5) until all the residuals are small. The procedure is said to be converging when the sum of the absolute values of the residuals is becoming smaller. It is assumed to have converged when this sum becomes less than a prescribed small number.

This procedure is a form of Newton's method (ref. 7) for determining the roots of a system of polynomials and, therefore, does not require the constitutive equations to be linear in displacement derivatives. In this report, however, only the linear equation (2) is used. The one requirement for the procedure is a reasonable first guess of the displacement of the body due to the boundary traction. It is shown in the examples, however, that these assumed values need not be very close to the true values. A flow chart of the procedure is presented and described in appendix $B$.

\section{EXAMPLES}

The numerical procedure is used to obtain approximate solutions for three stressconcentration problems. The first example illustrates the two-dimensional plane strain analysis of a rectangular plate which contains a central slit, the second illustrates the more practical three-dimensional analysis of a plate of finite thickness containing a rectangular slit through its thickness, and the third illustrates the case of a thick plate containing a semielliptical slit which extends only halfway through the thickness. The dimensions of these three plates are shown in figure 2. The elastic-plastic material prop-

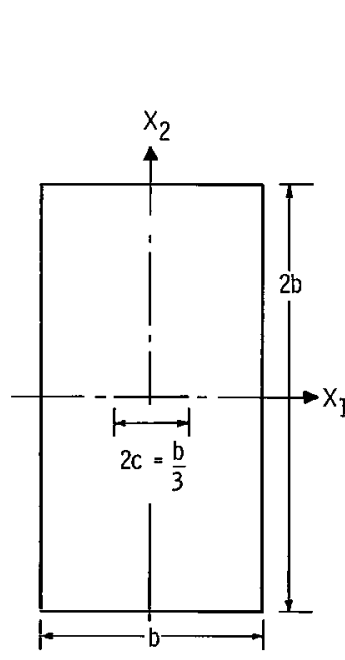

(a) Plane strain.

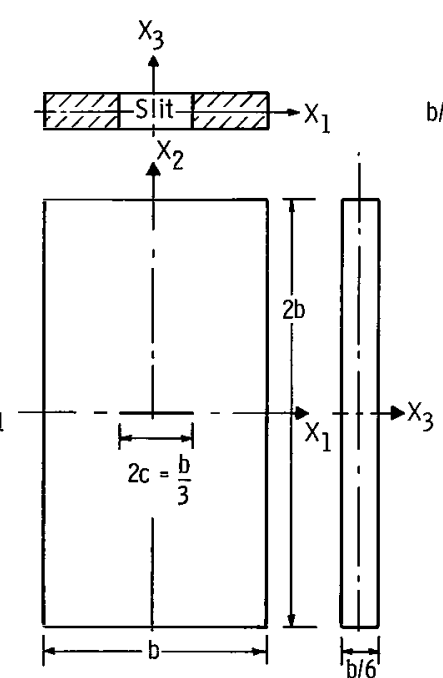

(b) Rectangular slit.

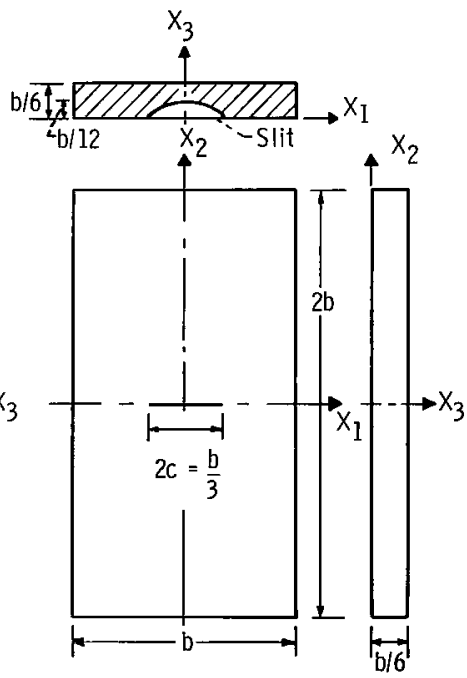

(c) Semielliptical slit.

Figure 2. - Example geometry. 
erties for all examples are as follows:

Young's modulus, $\mathrm{E}$, $\mathrm{ksi}\left(\mathrm{N} / \mathrm{m}^{2}\right) \ldots \ldots \ldots \ldots \ldots 10^{4}\left(2.06 \times 10^{11}\right)$ Poisson's ratio, $\nu \ldots \ldots \ldots \ldots \ldots \ldots \ldots \ldots \ldots$

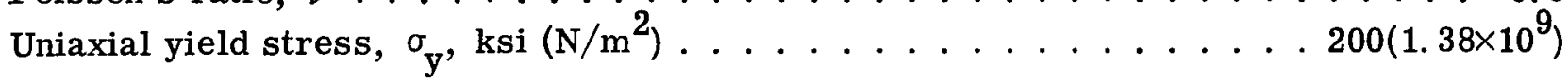

\section{Plane Strain}

The geometry of the first example is illustrated in figure 2(a). A uniform tension is applied in the $\mathrm{X}_{2}$ direction. No deformation occurs normal to the plane of the plate. The slit half-length $c$ equals $1 / 6$ of the plate width $b$.

Figure 3 shows a composite of the three successive grid patterns used to compute the elastic solution on one-quarter of the symmetrical plate. The method of choosing the successive grids is briefly stated as follows:

(1) The entire quarter plate is divided into squares with side length $b / 18$ (grid 1). The uniform tensile load is applied to the upper boundary of the plate (boundary line 1). In this example the displacement values for the plate without a slit are assumed for the

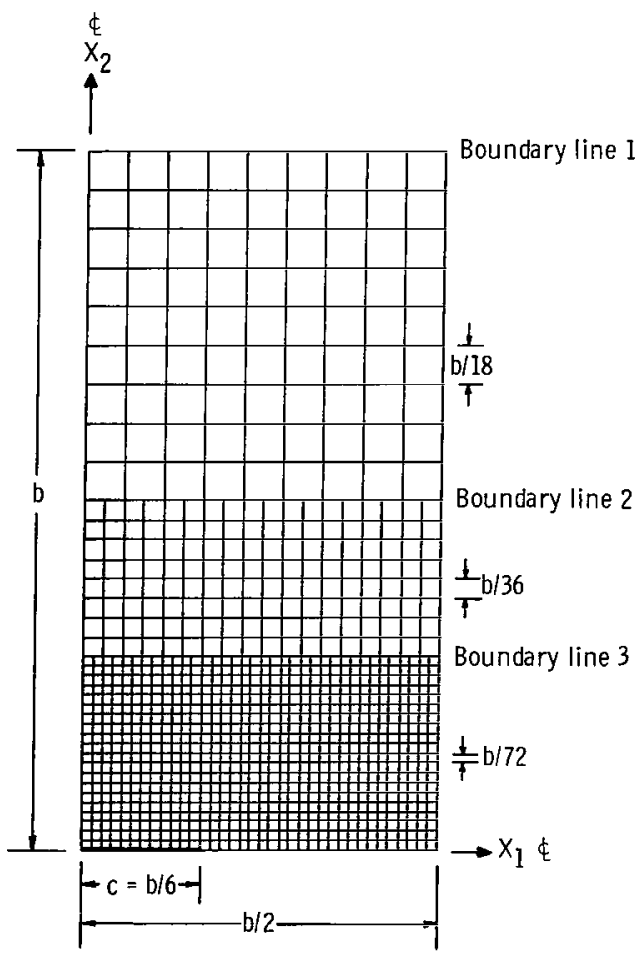

Figure 3. - Grid on one-quarter of plane strain example. 


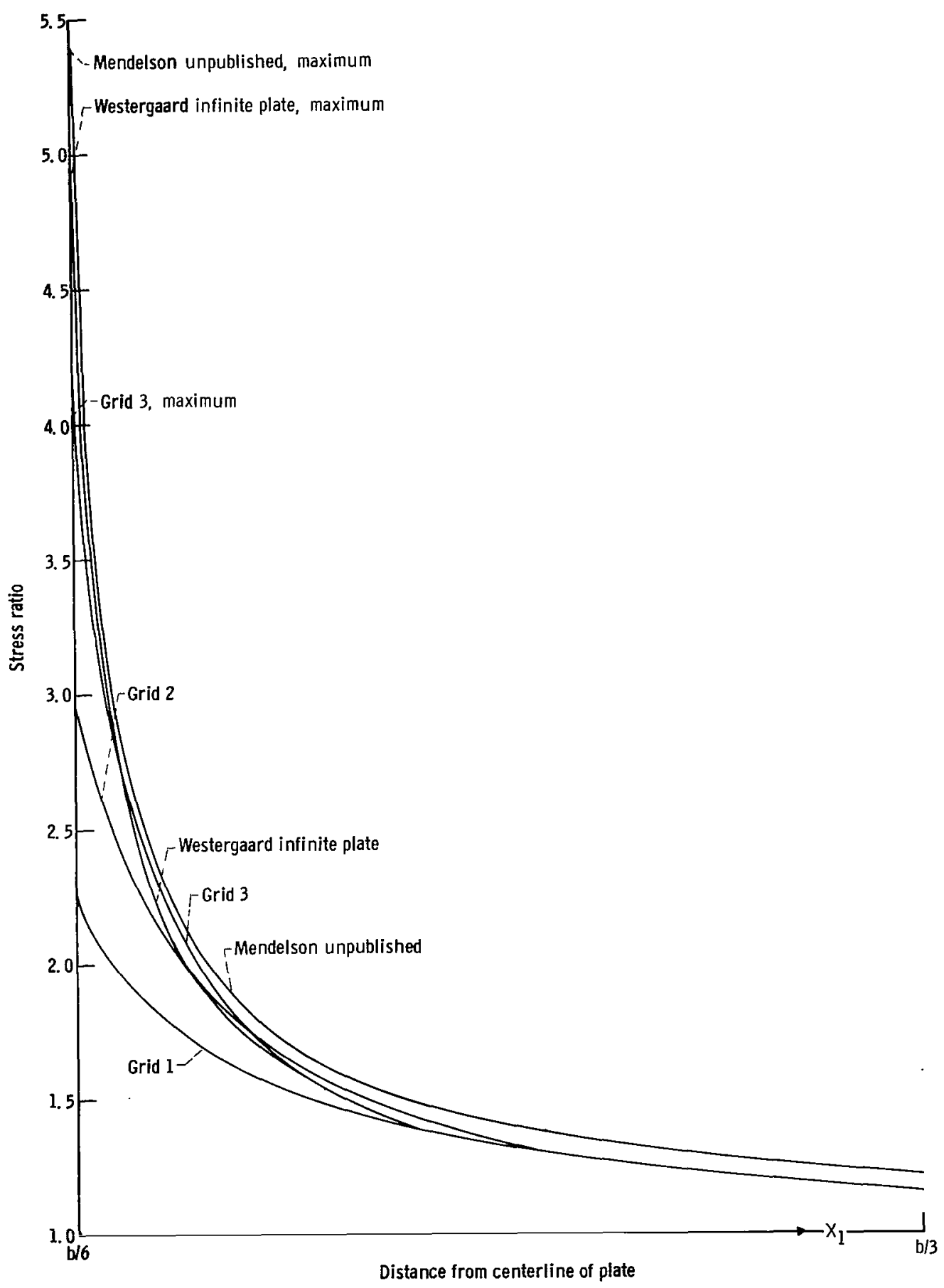

Figure 4. - Ratio of elastic stress ahead of slit in direction of load to remotely applied stress for plane strain example. 
first trial. The elastic solution for this grid and boundary condition is determined within a certain error by the numerical procedure.

(2) Stress values calculated on grid 1 are interpolated along boundary line 2. The displacements on grid 1 are interpolated to give an approximation to the solution of the elastic plate below boundary line 2 on the square grid with side length $\mathrm{b} / 36$ (grid 2). The elastic solution of this separate problem with a traction boundary condition prescribed at boundary line 2 is computed.

(3) Stresses calculated on grid 2 are interpolated along boundary line 3. The displacements on grid 2 are interpolated to give an approximation to the solution of the elastic plate below boundary line 3 on the square grid with side length $b / 72$ (grid 3 ). The solution of this final problem is considered the elastic solution for the plate in plane strain.

The technique of placing a more refined grid over a smaller area could be continued many times. These three grid sizes, however, establish the trend to be expected if more refined grids are used. The technique permits the use of a fine grid where the stress is expected to vary greatly with distance and a coarse grid wherethe stress is expected to be more nearly constant.

The stress ahead of the slit and normal to it calculated on each of the three square grids is presented in figure 4 and table $I$. The solutions of the elastic plane problems for an infinite plate with a slit $\mathrm{b} / 3$ in length (ref. 8), an infinite plate with a series of colinear slits $b / 3$ in length with centers $b$ apart (ref. 9), and an unpublished solution for the finite-width plate by A. Mendelson of the Lewis Research Center are shown for comparison. The variation of the stress distribution with grid size sets an obvious trend which appears reasonable when the analytical solutions are considered.

TABLE I. - RATIO OF ELASTIC STRESS AHEAD OF CRACK IN DIRECTION OF LOAD TO REMOTELY APPLIED STRESS FOR PLANE STRAIN EXAMPLE

\begin{tabular}{|c|c|c|c|c|c|c|c|c|c|c|c|c|c|}
\hline \multirow{2}{*}{$\begin{array}{c}\text { Stress } \\
\text { ratio }\end{array}$} & \multicolumn{13}{|c|}{ Distance from crack tip } \\
\hline & $\mathrm{c} / 48$ & $5 c / 48$ & $9 c / 48$ & $13 c / 48$ & $17 \mathrm{c} / 48$ & $21 c / 48$ & $25 c / 48$ & $29 \mathrm{c} / 48$ & $33 c / 48$ & $37 \mathrm{c} / 48$ & $41 c / 48$ & $45 c / 48$ & $49 c / 48$ \\
\hline Grid 1 & 2.13 & --- & --- & --- & 1.44 & --- & --- & --- & 1.25 & --- & --- & --- & 1.15 \\
\hline Grid 2 & 3.00 & --- & 1.86 & --- & 1.51 & - & 1.34 & --- & 1.25 & --- & 1.19 & $-\cdots$ & 1. 15 \\
\hline Grid 3 & 4. 13 & 2.43 & 1.89 & 1.62 & 1.47 & 1.38 & 1.31 & 1.27 & 1.23 & 1.20 & 1.18 & 1. 16 & 1.15 \\
\hline $\begin{array}{l}\text { Infinite plate } \\
\text { (ref. 8) }\end{array}$ & 4.93 & 2.34 & 1.84 & 1. 61 & 1. 47 & 1.38 & 1.32 & 1.27 & 1. 23 & 1.21 & 1. 18 & 1. 16 & 1. 15 \\
\hline $\begin{array}{l}\text { Colinear slits } \\
\text { (ref. 9) }\end{array}$ & 5.16 & 2.45 & 1. 93 & 1.69 & 1.55 & 1.45 & 1.39 & 1. 34 & 1.30 & 1. 27 & 1. 25 & 1. 23 & 1. 21 \\
\hline $\begin{array}{l}\text { Mendelson } \\
\text { (unpublished) }\end{array}$ & 5.40 & 2.47 & 1.95 & 1.71 & 1.57 & 1.47 & 1.41 & 1. 36 & 1.32 & 1.28 & 1.26 & $-\ldots$ & --- \\
\hline
\end{tabular}




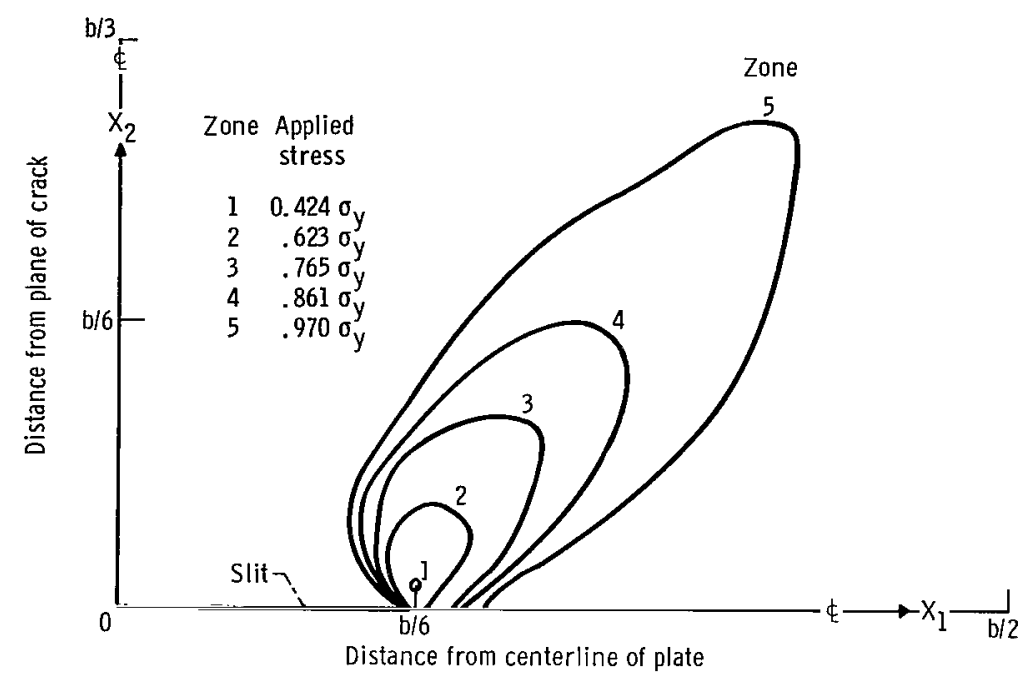

Figure 5. - Plastic zone size for plane strain example.

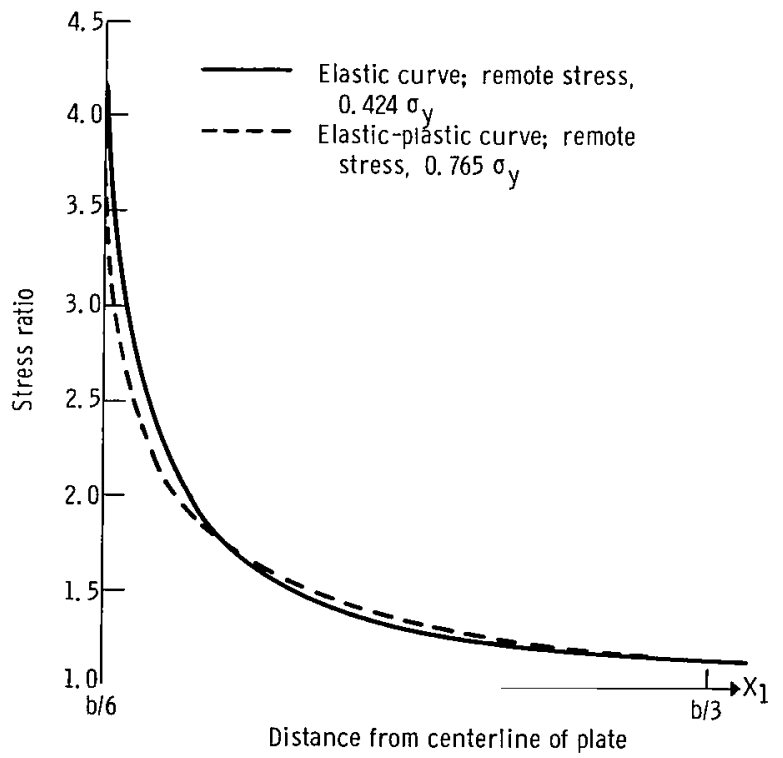

Figure 6. - Ratio of elastic-plastic stress ahead of slit in direction of load to remotely applied stress for plane strain example. 
In order to calculate the analytical solutions, the exact location of the end of the slit must be known. The numerical procedure requires only that the grid points on the slit be considered traction-free boundary points and that the grid points not slit be considered interior points. The end of the slit then lies somewhere between two grid points. The uniform tensile load deforms the slit into a nearly elliptical shape. Extrapolation of the displacement of the grid points on the slit provides an estimate of the location of the tip of the slit where no displacement in the $\mathrm{x}_{2}$ direction occurs. This value is approximately one-quarter of a grid space before the first interior grid point in the line of the slit. This more precise crack length of $(11.75 / 12.00)(b / 3)$ is used to calculate the analytical solutions shown in figure 4 and table $I$.

The first grid point (on grid 3) yields at an applied gross tension of $0.424 \sigma \mathrm{y}$. The plate above boundary line 3 is assumed to remain elastic and to remain unaffected by the growth of the plastic zone near the tip of the slit. After initial yielding, the load on grid 3 was increased by 3 percent of the previous load for 28 increments. In order to obtain a fairly rapid solution, a fixed small number of iterations (30) was employed for each increment. The growth of the plastic zone is illustrated in figure 5 for various applied tensile loads. The redistribution of stress ahead of the slit and normal to it due to the plasticity of the material is illustrated in figure 6 for one particular load.

The convergence of the elastic solution on the three successive grids is shown in figure 7. In this figure the mean residual (i.e., the sum of the absolute value of the re-

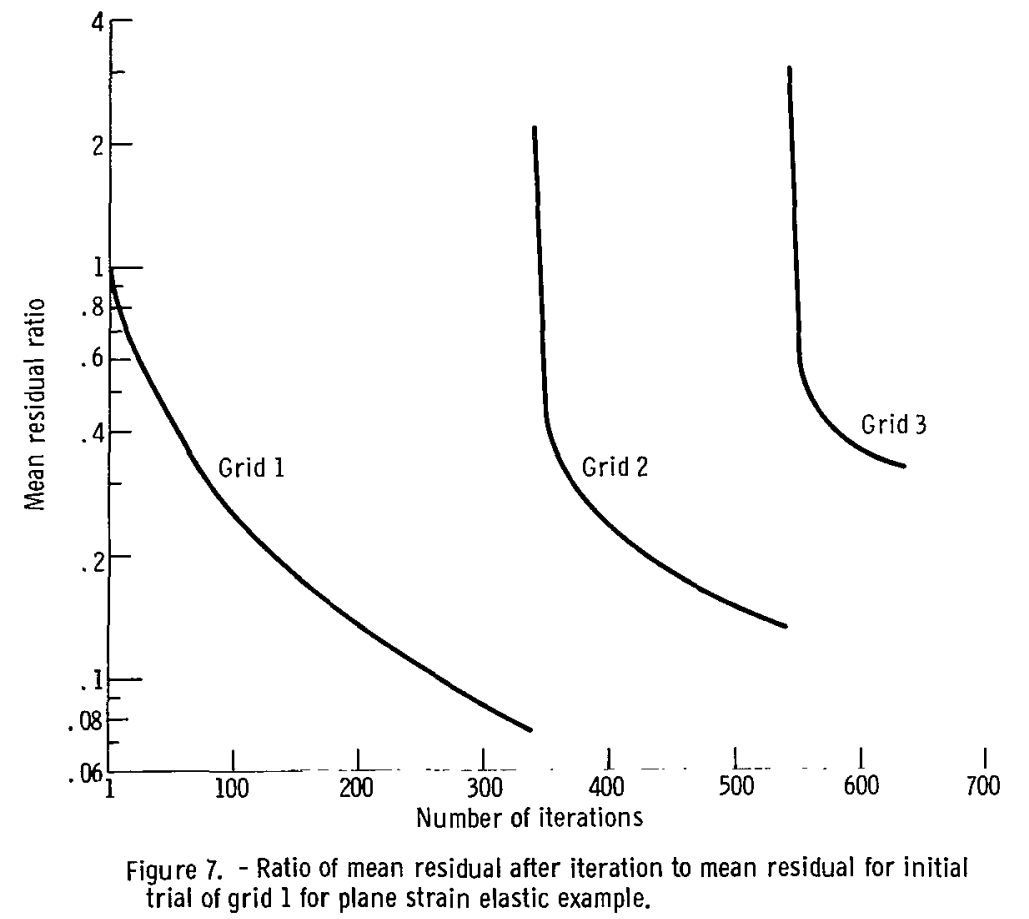


siduals divided by the number of grid points) is plotted against increasing number of iterations. For each grid the mean residual of the finite difference equations decreases with increasing iterations. As the grid boundary comes close to the slit, the mean residual increases because a greater percentage of grid points are very near the slit.

The relaxation factor chosen for this two-dimensional problem was 1.0 because it was found by trial and error that numbers greater than 1.0 decreased the rate of convergence and numbers less than 1.0 caused oscillation or divergence of the solution. The iteration was stopped for each grid when the increment $\mathrm{DU}_{\mathrm{i}}$ to every displacement component $\mathrm{U}_{\mathrm{i}}$ satisfied the condition

$$
\mathrm{DU}_{\mathrm{i}}<\frac{\mathrm{U}_{\mathrm{i}}}{1 \times 10^{4}}+10^{-6}
$$

The second term $\left(10^{-6}\right)$ on the right side of expression (8) was chosen to be about the

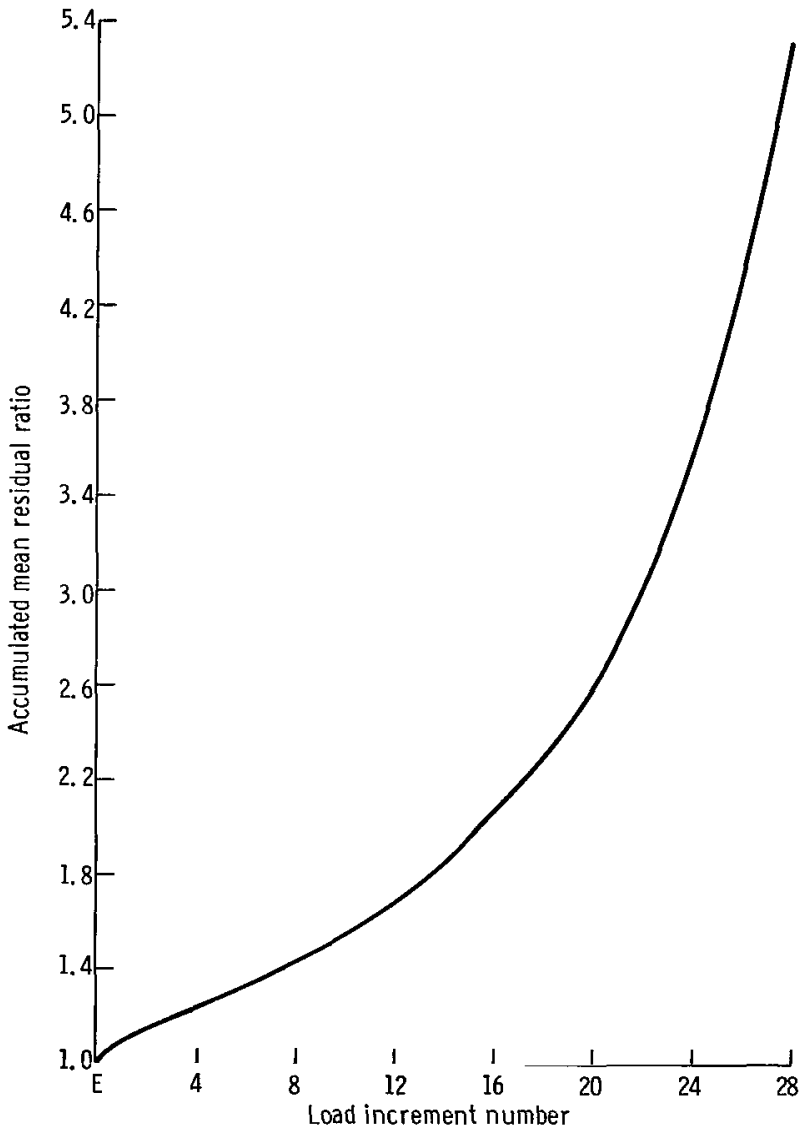

Figure 8. - Ratio of accumulated mean residual to mean residual for elastic solution for elastic-plastic plane strain example.

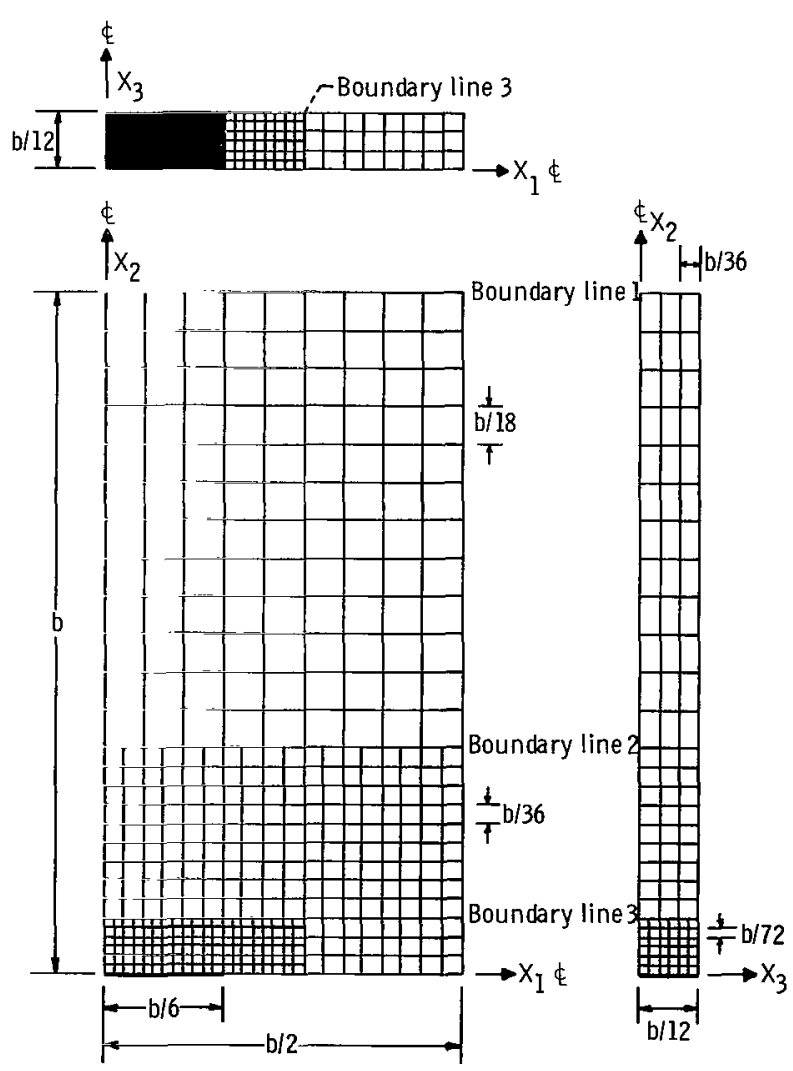

Figure 9. - Grid on one-eighth of rectangular slit example. 
same magnitude as the first term. This expedient is needed for those stations where the displacement is zero.

Figure 8 illustrates the growth of the mean residual with the number of load increments. As the plastic zone size increases, the mean residual becomes large because a fixed number of iterations are employed. The large zones illustrated in figure 5 are calculated from stress values that may contain five times as much error as the elastic solution. The residuals could be reduced to any prescribed amount, however, by allowing a greater number of iterations for each loading increment. The largest zone, at a load of $0.970 \sigma_{\mathrm{y}}$, reaches boundary line 3 and, therefore, violates the assumption that boundary line 3 would remain unaffected. These large zone sizes then must be considered only as trends.

\section{Rectangular Slit}

The geometry of the second example is illustrated in figure 2(b). The thick plate contains a rectangular slit of length $\mathrm{b} / 3$ which extends entirely through its thickness. Figure 9 shows, on one-eighth of the symmetrical plate, the three successive grids that were employed. The technique of refining the grid near the slit is exactly as discussed for the plane strain example. In this case the extent of each grid was determined primarily by computer core storage limitations.

The elastic stress ahead of the slit and normal to it due to the uniform tensile load in the $\mathrm{x}_{2}$ direction is shown in figure 10 for the center of the plate $\left(\mathrm{X}_{3}=0\right)$ and for the face $\left(X_{3}=b / 12\right)$ for each of the three successive grids. The stresses show the same trends with successively smaller grid sizes as those in the plane strain example. The

variation of the stresses $T_{11}, T_{22}, T_{33}$ through the thickness of the plate is illustrated in figure 11 and compared with the plane strain values calculated in the previous example. These results demonstrate the same trends as the stresses near a hole in a thick plate calculated by other authors (refs. 10 and 11).

The first grid point (grid 3) yields at an applied gross tension of $0.338 \sigma_{\mathrm{y}^{\circ}}$ Since the boundary line 3 is near the slit, it is not reasonable to assume that the material on that line would be unaffected by the growth of the plastic zone. Therefore, it is assumed that the plate above boundary line 2 remains elastic and unaffected by the plastic zone. For each load increment then, the elastic-plastic solution on both grids 2 and 3 must be computed. After initial yielding, the uniform tension was increased by 3 percent of the previous load for 30 increments. The growth of the plastic zone normal to the slit at the center of the plate $\left(\mathrm{X}_{3}=0\right)$ and at the face $\left(\mathrm{X}_{3}=\mathrm{b} / 12\right)$ is shown in figures 12 and 13 , respectively. 


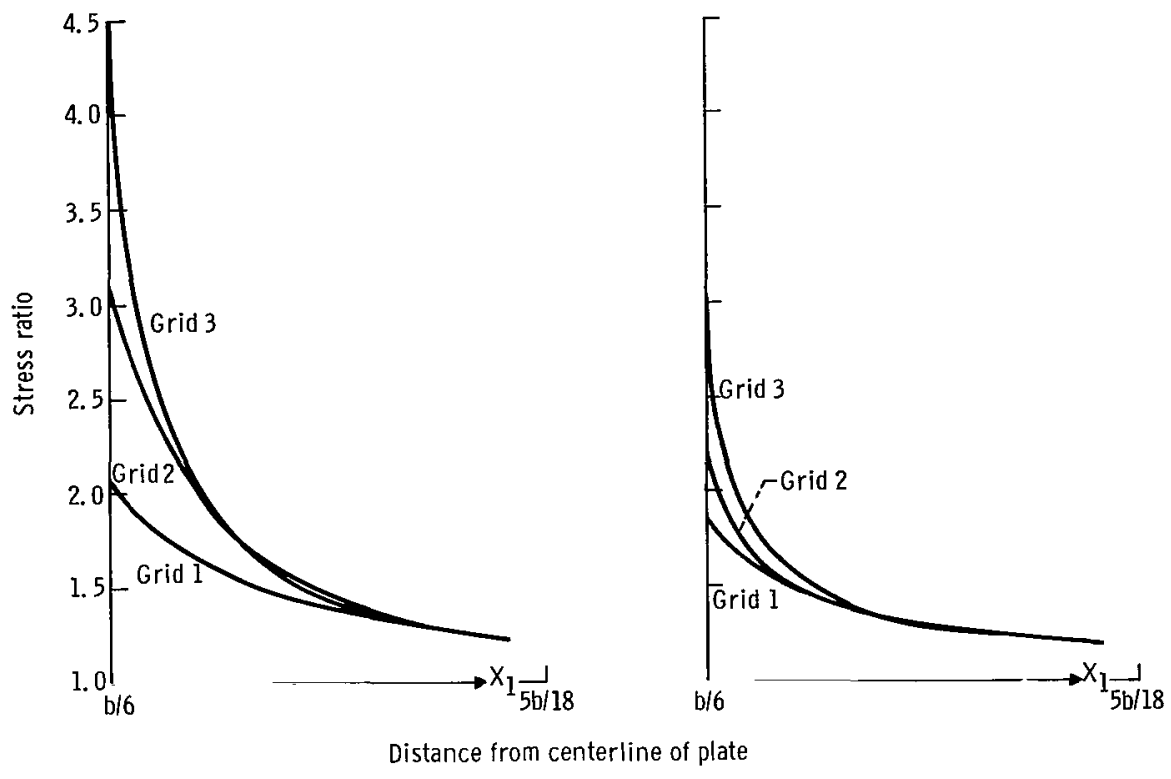

$\begin{array}{ll}\text { (a) Stress in plane } x_{3}=0 . & \text { (b) Stress in plane } x_{3}=b / 12 .\end{array}$

Figure 10. - Ratio of elastic stress ahead of slit in direction of load to remotely applied stress for rectangular slit example.

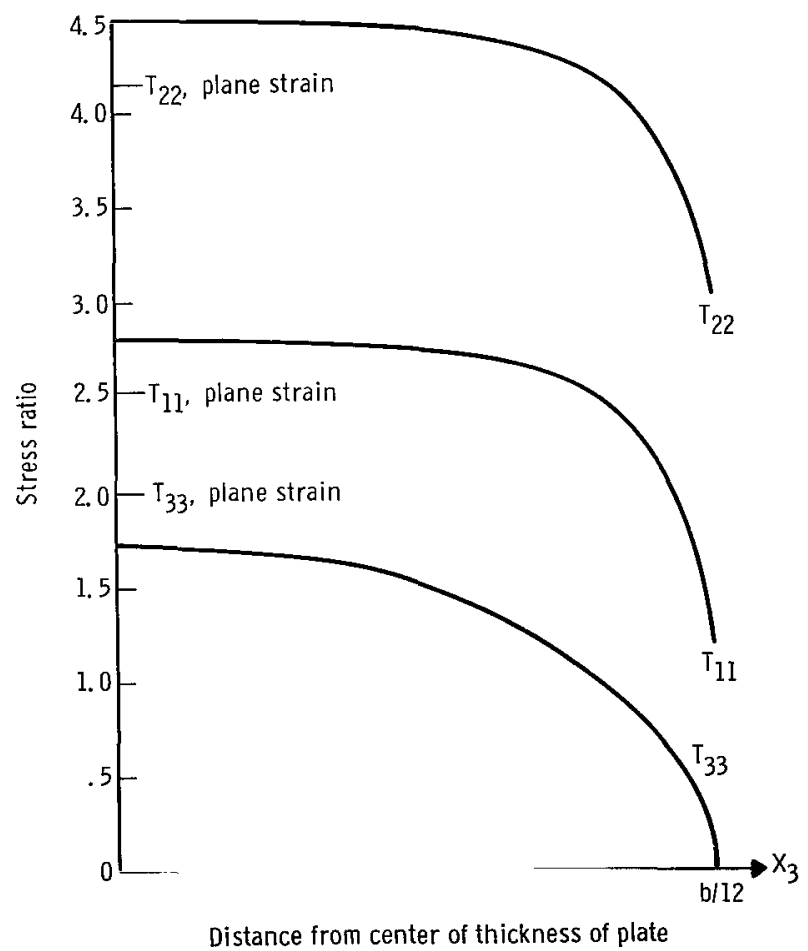

Figure 11. - Variation of ratio of elastic stress ahead of slit to remotely applied stress through thickness for rectangular slit example. 


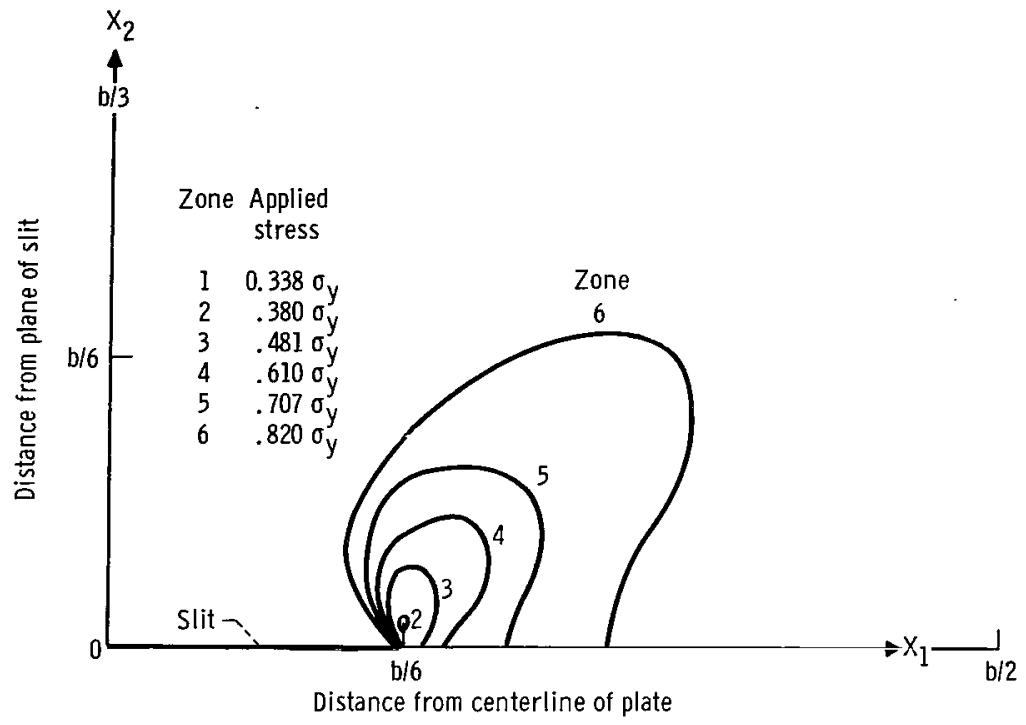

Figure 12. - Plastic zone size in plane $x_{3}=0$ for rectangular slit example.

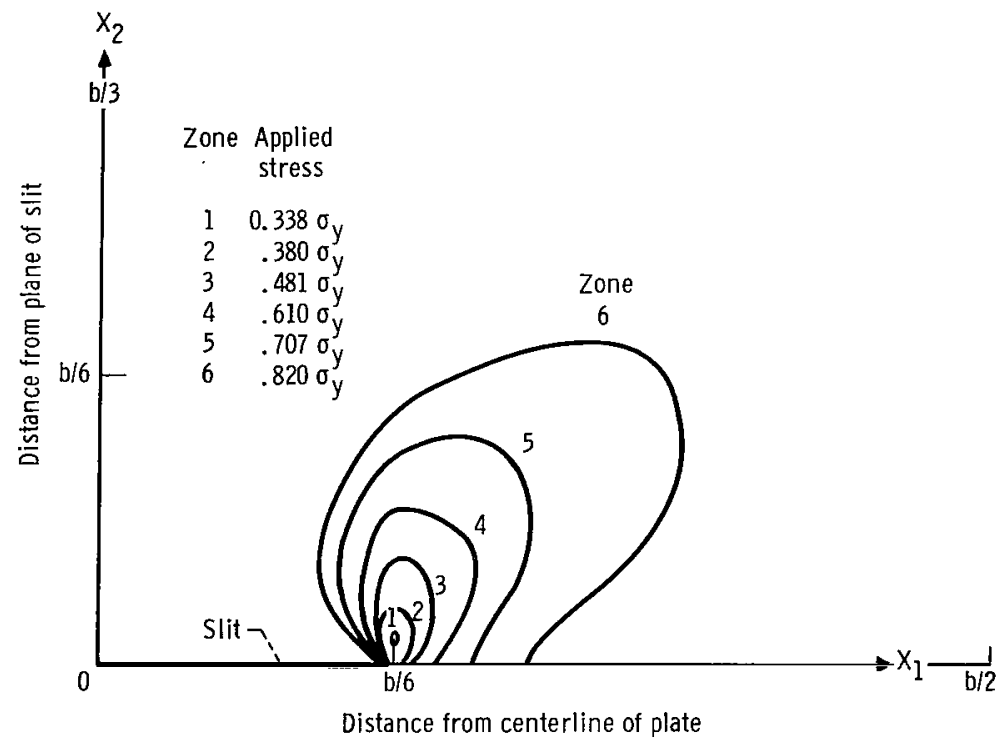

Figure 13. - Plastic zone size in plane $x_{3}=b / 12$ for rectangular slit example. 


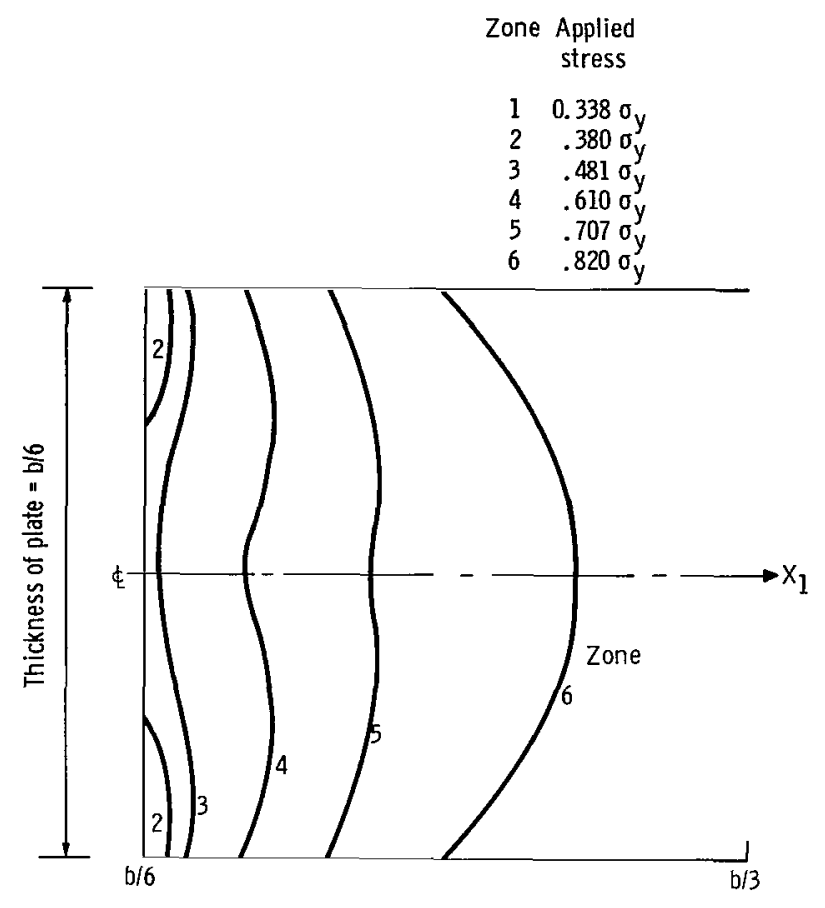

Figure 14. - Plastic zone size in plane of slit $\left(X_{2}=0\right)$ for rectangular
slit example.

Figure 14 shows the growth of the plastic zone ahead of the slit in the plane of the slit. This figure shows that the plastic zone does not extend to the center of the plate when the zone is small. At larger applied loads, the zone extends through the plate and becomes greater at the centerline than at the faces.

The convergence of this example is similar to the convergence of the plane strain example. Expression (8) is employed as the convergence criterion for the elastic solution. Thirty iterations were performed for each load increment; therefore, the growth of the mean residual with increasing plastic zone size is also similar to that described in the previous example.

A relaxation factor of 1.4 was chosen to assure convergence of the procedure. For three-dimensional problems the relaxation factor 1.0 causes rapid divergence. Relaxation factors larger than 1.4 assure convergence at a slower rate.

\section{Semielliptical Slit}

The geometry of the final example is illustrated in figure $2(\mathrm{c})$. The thick plate contains a semielliptical slit with a major half axis of $\mathrm{b} / 6$ and a minor half axis equal to 


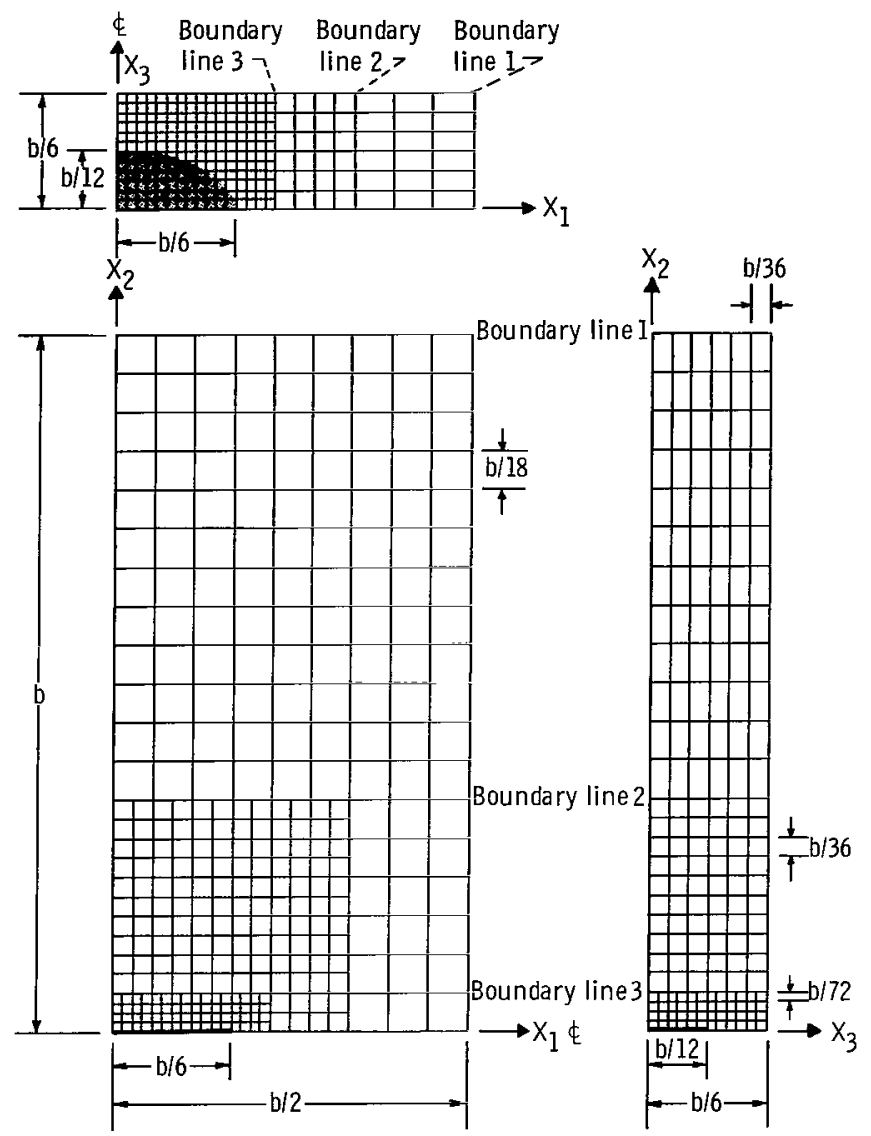

Figure 15. - Grid on one-quarter of semielliptical slit example.

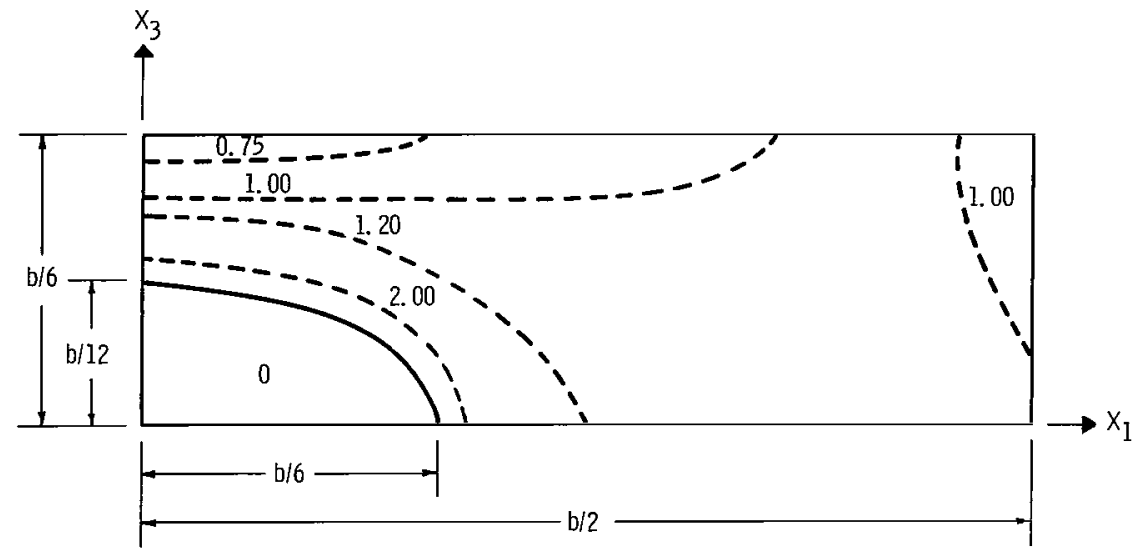

Figure 16. - Elastic stress in direction of load in plane of semielliptical slit. Contours of ratio of stress to remotely applied stress. 
$\mathrm{b} / 12$ or half the thickness of the plate. As in the other examples, three successive grids were employed to compute the elastic stress distribution. The extent of the grids, determined primarily by computer core storage limitations, is shown on one-quarter of the symmetrical plate, in figure 15. The initial trial displacements on grid 1 are approximations to the analogous plane stress problem in each $\left(x_{1}, x_{2}\right)$ grid plane in the $x_{1}$ and $\mathrm{x}_{2}$ directions and zero in the $\mathrm{x}_{3}$ direction.

Contours of elastic stress in the plane of the slit and normal to it due to the uniform tensile load in the $x_{2}$ direction are drawn in figure 16. The first grid point (grid 3)

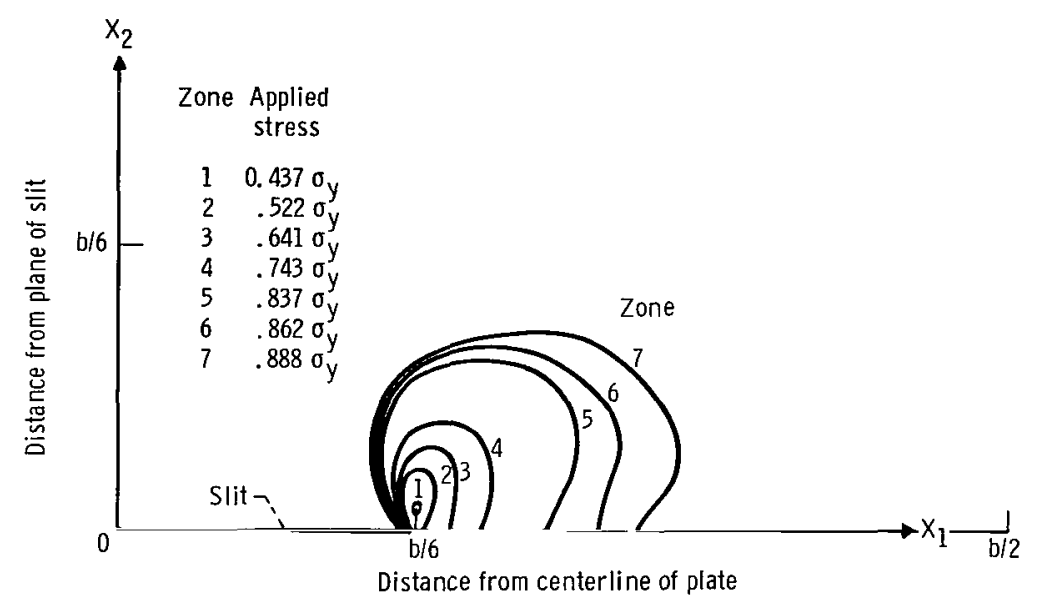

Figure 17. - Plastic zone size in plane $x_{3}=0$ for semielliptical slit example.

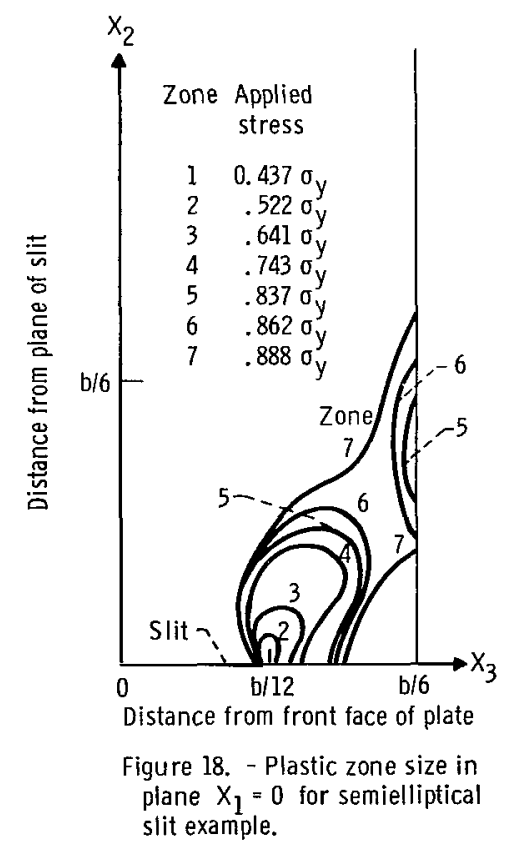




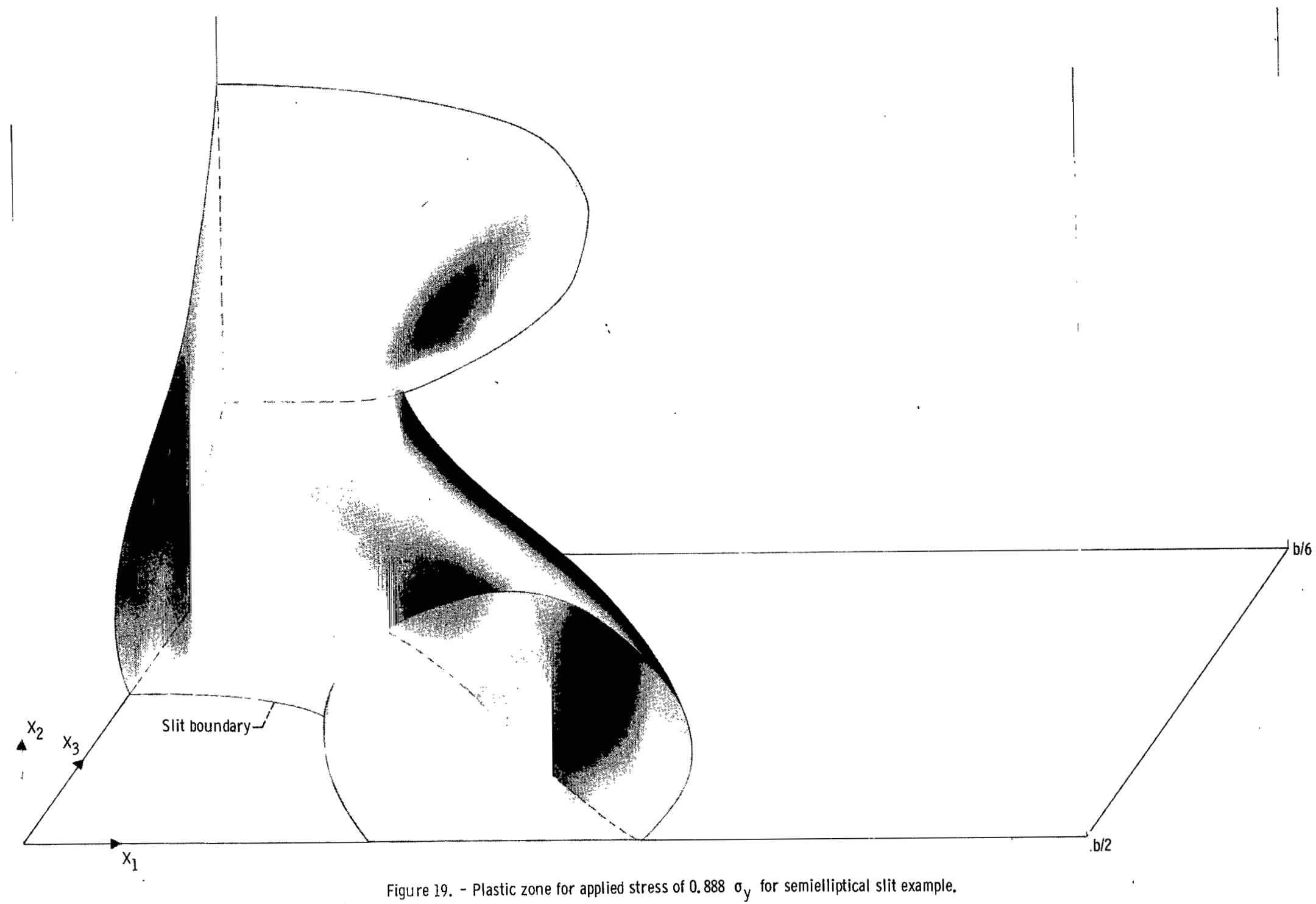


yields at an applied gross tension of $0.437 \sigma_{\mathrm{y}}$. As in the previous example, the part of the plate above boundary line 2 is assumed to be unaffected by the plastic zone growth, and the elastic-plastic solution must be computed on both grid 2 and grid 3 for each load increment. After initial yielding, the uniform tensile load was increased by 3 percent of the previous load for 24 increments. The plastic zone growth on the face containing the slit is illustrated in figure 17. The zone growth through the thickness to the back face of the plate is shown in figure 18. Notice that the zone grows from the slit tip and then joins with another zone initiated on the back face. The stress on the back face directly ahead of the slit is still at a low elastic stress. A three-dimensional sketch of the plastic zone at applied stress of $0.888 \sigma_{\mathrm{y}}$ is shown in figure 19 for one-quarter of the symmetrical plate.

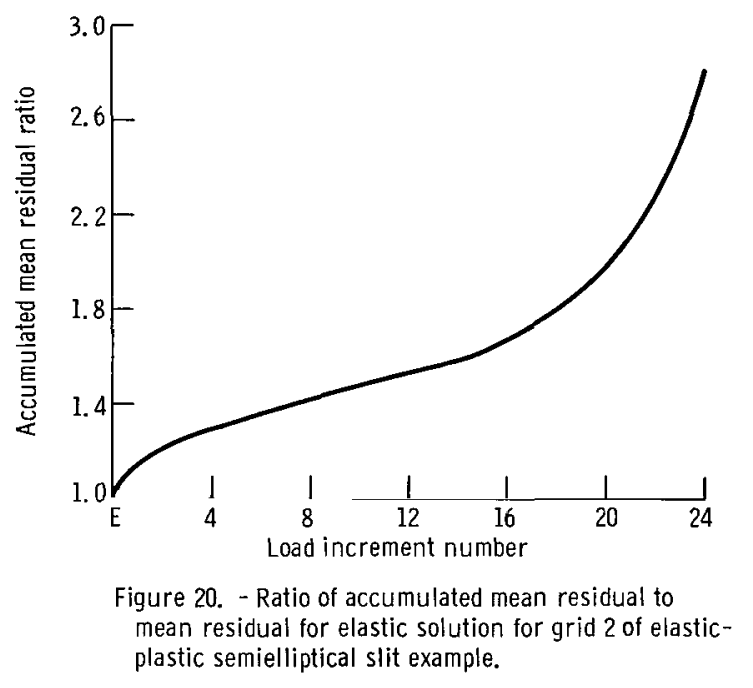

The convergence of this example required a relaxation factor of at least 1.4. As in the previous three-dimensional example, values less than 1.4 caused rapid divergence. Expression (8) was employed as the convergence criterion for the elastic solution, and 30 iterations were performed for every load increment beyond the initial yield point. The mean residual thus behaves similarly to that discussed in the plane strain example. The mean residual growth during increasing load and plastic zone size is illustrated in figure 20. As discussed in the section Plane Strain, a greater number of iterations for each increment could reduce the mean residual to any desired amount. 


\section{DISCUSSION}

There are several requirements that a new numerical procedure must fulfill. First, it must produce an answer, that is, it must converge. In the three examples illustrated, the convergence is monotonic; thus, the error is controlled by the number of iterations. A relaxation factor, based on the number of dimensions, grid element shape, Poisson's ratio, and perhaps other parameters, must be chosen wisely. In all cases attempted, relaxation factors of 1.0 and 1.4 appear satisfactory for two- and three-dimensional examples, respectively. These values were determined experimentally, however, and no theoretical justification has been made. The requirement that a reasonable first approximation be made is apparently not harsh since the trivial value of uniform tension permits convergence.

Another requirement of a numerical procedure is that it produce results of useful accuracy. The present numerical results can be compared with analytical solutions for plane examples, and the trends in some three-dimensional problems can be compared with other problems that have been solved. The numerical results of the plane strain example compare favorably with the analytical solutions of similar problems. The stress variation through the thickness of the plate with the rectangular slit illustrates the same trends that occur in the exact solution of other related problems.

A final criterion by which to judge a numerical method is economy. Table II lists the computer running time on the NASA Lewis IBM 7044/7094II for the three examples. These times are much less than those required to solve problems involving fewer un-

TABLE II. - COMPUTER RUNNING TIME ON IBM 7044/7094I

\begin{tabular}{|c|c|c|c|c|c|c|}
\hline \multirow{2}{*}{ Grid } & \multicolumn{5}{|c|}{ Problem } \\
\cline { 2 - 7 } & \multicolumn{2}{|c|}{ Plane strain } & \multicolumn{2}{c|}{ Rectangular slit } & \multicolumn{2}{c|}{ Semielliptical slit } \\
\cline { 2 - 7 } & $\begin{array}{c}\text { Time, } \\
\text { min }\end{array}$ & $\begin{array}{c}\text { No. of } \\
\text { increments }\end{array}$ & $\begin{array}{c}\text { Time, } \\
\text { min }\end{array}$ & $\begin{array}{c}\text { No. of } \\
\text { increments }\end{array}$ & $\begin{array}{l}\text { Time, } \\
\text { min }\end{array}$ & $\begin{array}{c}\text { No. of } \\
\text { increments }\end{array}$ \\
\hline Elastic: & & & & & & \\
1 & 2.81 & -- & 7.00 & -- & 29.28 & -- \\
2 & 3.04 & -- & 10.98 & -- & 23.53 & - \\
3 & 3.23 & -- & 17.18 & -- & 21.76 & -- \\
& 9.08 & & 35.16 & & 74.57 & \\
\hline Plastic: & & & & & & \\
2 & 0 & 0 & 70.72 & 30 & 61.68 & 24 \\
3 & 53.11 & 28 & 60.71 & 18 & 75.74 & 22 \\
\hline Total time & 62.19 & & 166.59 & & 211.99 & \\
\hline
\end{tabular}


knowns by the matrix displacement method of Argyris (ref. 3). In order to obtain better precision, however, times much greater than those listed may be required. Since it is less expensive to use a smaller computer, storage minimization is also an economy. The only quantities that need to be stored for each grid point at any particular load increment are six stress and three displacement components calculated for the previous increment and three displacement and three stiffness coefficient components (the quantities $\left.\left(R_{i, 1}-R_{i, 2}\right) / d\right)$ for the current increment. The most important economy is convenience, however, since the method can be employed on any farily large computer with no peripheral storage or other special equipment. Although the problems considered herein have not included strain hardening, the method is sufficiently general to allow the use of various material properties including arbitrary strain hardening.

\section{CONCLUDING REMARKS}

The iterative procedure presented herein was found to be convergent. The error in the solution of the difference equations is known after every iteration and can be controlled by the number of iterations. The procedure can be used on most large computers presently available because a minimum of core storage and no peripheral storage is required. The running time for problems involving thousands of simultaneous equations is moderate. The stress values calculated in the elastic plane strain analysis of a plate containing a central slit were compared with an analytical solution of Westergaard and are in good agreement. Although no exact comparisons are available for the threedimensional examples, high confidence is placed in the usefulness of the procedure because of its performance on the two-dimensional problem.

Lewis Research Center,

National Aeronautics and Space Administration, Cleveland, Ohio, April 23, 1968, 124-08-06-01-22. 


\section{APPENDIX A}

\section{FINITE DIFFERENCE EQUATIONS}

In this study the conventional finite difference approximations to derivatives were used. For the first-order derivatives these are

$$
\frac{\partial U_{i}}{\partial X_{j}}=\left\{\begin{array}{cc}
\frac{-3 U_{i}\left(X_{j}\right)+4 U_{i}\left(X_{j}+h_{j}\right)-U_{i}\left(X_{j}+2 h_{j}\right)}{2 h_{j}} & \text { (forward) } \\
\frac{U_{i}\left(X_{j}+h_{j}\right)-U_{i}\left(X_{j}-h_{j}\right)}{2 h_{j}} & \text { (central) } \\
\frac{3 U_{i}\left(X_{j}\right)-4 U_{i}\left(X_{j}-h_{j}\right)+U_{i}\left(X_{j}-2 h_{j}\right)}{2 h_{j}} & \text { (backward) }
\end{array}\right.
$$

Second-order derivatives are written as

$$
\frac{\partial^{2} U_{i}}{\partial X_{j}^{2}}=\frac{U_{i}\left(X_{j}+h_{j}\right)-2 U_{i}\left(X_{j}\right)+U_{i}\left(X_{j}-h_{j}\right)}{h_{j}^{2}}
$$

$$
\begin{aligned}
& \frac{\partial^{2} U_{i}}{\partial x_{j} \partial x_{i}}=\frac{U_{i}\left(x_{j}+h_{j}, x_{i}+h_{i}\right)-U_{i}\left(x_{j}-h_{j}, x_{i}+h_{i}\right)}{4 h_{j} h_{i}} \\
& \quad \frac{+U_{i}\left(x_{j}-h_{j}, x_{i}-h_{i}\right)-U_{i}\left(x_{j}+h_{j}, x_{i}-h_{i}\right)}{4 h_{j} h_{i}}, i \neq j
\end{aligned}
$$

At the interior point ahead of the crack tip the special condition $\partial \mathrm{U}_{2} / \partial \mathrm{X}_{1} \partial \mathrm{X}_{2}=$ $\partial \mathrm{U}_{2} / \partial \mathrm{X}_{3} \partial \mathrm{X}_{2}=0$ is used. Other approximations to these derivatives ahead of the crack tip were investigated and very little diffe rence was found in the stresses calculated.

The finite difference boundary equation (eq. (6)) is obtained by substituting the firstorder differences into the $\Delta T_{i j}$ term of the equation 


$$
T_{i j}+\Delta T_{i j}-\text { Applied stress }=T_{i p}=0
$$

which describes equilibrium at the boundary.

For the equilibrium equations for the interior of the body, derivatives of the stress components must be computed. For example, the first term of the equilibrium equation in the $\mathrm{x}_{1}$ direction can be written as

$$
\Delta \frac{\partial \mathrm{T}_{11}}{\partial \mathrm{X}_{1}}=2 \mathrm{G}\left\{\Delta \frac{\partial \epsilon_{11}}{\partial \mathrm{X}_{1}}-\Delta \frac{\partial \mathrm{e}}{\partial \mathrm{X}_{1}}-\frac{1}{2 \mathrm{k}^{2}} \frac{\partial}{\partial \mathrm{X}_{1}}\left[\Delta \mathrm{W}\left(\mathrm{T}_{11}-\mathrm{S}\right)\right]\right\}+3 \mathrm{~K} \Delta \frac{\partial \mathrm{e}}{\partial \mathrm{X}_{1}}
$$

where

$$
\begin{gathered}
\Delta \frac{\partial \epsilon_{11}}{\partial \mathrm{X}_{1}}=\left.\frac{\partial^{2} \mathrm{U}_{1}}{\partial \mathrm{X}_{1}^{2}}\right|_{1}-\left.\frac{\partial^{2} \mathrm{U}_{1}}{\partial \mathrm{X}_{1}^{2}}\right|_{0} \\
\Delta \frac{\partial \mathrm{e}}{\partial \mathrm{X}_{1}}=\left.\frac{1}{3}\left(\frac{\partial^{2} \mathrm{U}_{1}}{\partial \mathrm{X}_{1}^{2}}+\frac{\partial^{2} \mathrm{U}_{2}}{\partial \mathrm{X}_{1} \partial \mathrm{X}_{2}}+\frac{\partial^{2} \mathrm{U}_{3}}{\partial \mathrm{X}_{1} \partial \mathrm{X}_{3}}\right)\right|_{1}-\left.\frac{1}{3}\left(\frac{\partial^{2} \mathrm{U}_{1}}{\partial \mathrm{X}_{1}^{2}}+\frac{\partial^{2} \mathrm{U}_{2}}{\partial \mathrm{X}_{1} \partial \mathrm{X}_{2}}+\frac{\partial^{2} \mathrm{U}_{3}}{\partial \mathrm{X}_{1} \partial \mathrm{X}_{3}}\right)\right|_{0}
\end{gathered}
$$

$$
\begin{aligned}
& \frac{\partial}{\partial \mathrm{X}_{1}}\left[\Delta \mathrm{W}\left(\mathrm{T}_{11}-\mathrm{S}\right)\right] \\
& \quad=\frac{\Delta \mathrm{W}\left(\mathrm{X}_{1}+\mathrm{h}_{1}\right)\left[\mathrm{T}_{11}\left(\mathrm{X}_{1}+\mathrm{h}_{1}\right)-\mathrm{S}\left(\mathrm{X}_{1}+\mathrm{h}_{1}\right)\right]-\Delta \mathrm{W}\left(\mathrm{X}_{1}-\mathrm{h}_{1}\right)\left[\mathrm{T}_{11}\left(\mathrm{X}_{1}-\mathrm{h}_{1}\right)-\mathrm{S}\left(\mathrm{X}_{1}-\mathrm{h}_{1}\right)\right]}{2 \mathrm{~h}_{1}}
\end{aligned}
$$

where $\left.\mathrm{U}\right|_{1}$ is evaluated at the present load level and $\left.\mathrm{U}\right|_{0}$ is evaluated at the previous load level.

The finite difference equilibrium equation (eq. (5)) is obtained by substituting the finite difference forms of the first- and second-order derivatives of $\mathrm{U}$ into the $\Delta \partial \mathrm{T}_{\mathrm{ij}} / \partial \mathbf{X}_{\mathrm{j}}$ terms of equation (4). 


\section{APPENDIX B}

\section{FLOW CHART OF NUMERICAL PROCEDURE}

A more precise description of the numerical procedure is presented in the flow chart of figure 21. The initial trial displacements are established and a grid point is chosen. Loop 1 computes the quantities $R_{1,1}, R_{2,1}, R_{3,1}$ by substituting the trial displacements into the traction boundary or equilibrium equations. It then computes $R_{1,2}$, $\mathrm{R}_{2,2}, \mathrm{R}_{3,2}$ by altering the displacement in the $\mathrm{x}_{1}, \mathrm{x}_{2}, \mathrm{x}_{3}$ directions, respectively, by an arbitrary amount $d$. These values are used to determine the approximation to the slope of the $R\left(U_{i}\right)$ curve shown in figure 1 (p. 6). For linear problems this slope, $R S_{i}$, will be the same for any value of $U_{i}$ at a particular grid point. For nonlinear problems the $\mathrm{RS}_{\mathrm{i}}$ values must be recalculated after the trial displacement values have changed appreciably.

Loop 2 computes the slope of the lines connecting $R_{i, 1}$ and $R_{i, 2}$ for $i=1 \ldots 3$. Loop 3 calculates the new displacement value according to equation(7). Loop 4 repeats this process for every point in the grid starting at $\left(\mathrm{X}_{1}, \mathrm{X}_{2}, \mathrm{X}_{3}\right)=(0,0,0)$ and moving in the $\mathrm{X}_{1}, \mathrm{X}_{2}, \mathrm{X}_{3}$ directions successively. Loop 5 repeats the process for the entire grid until convergence or a prescribed number of iterations is performed. Loop 6 repeats the entire procedure for each load increment. 


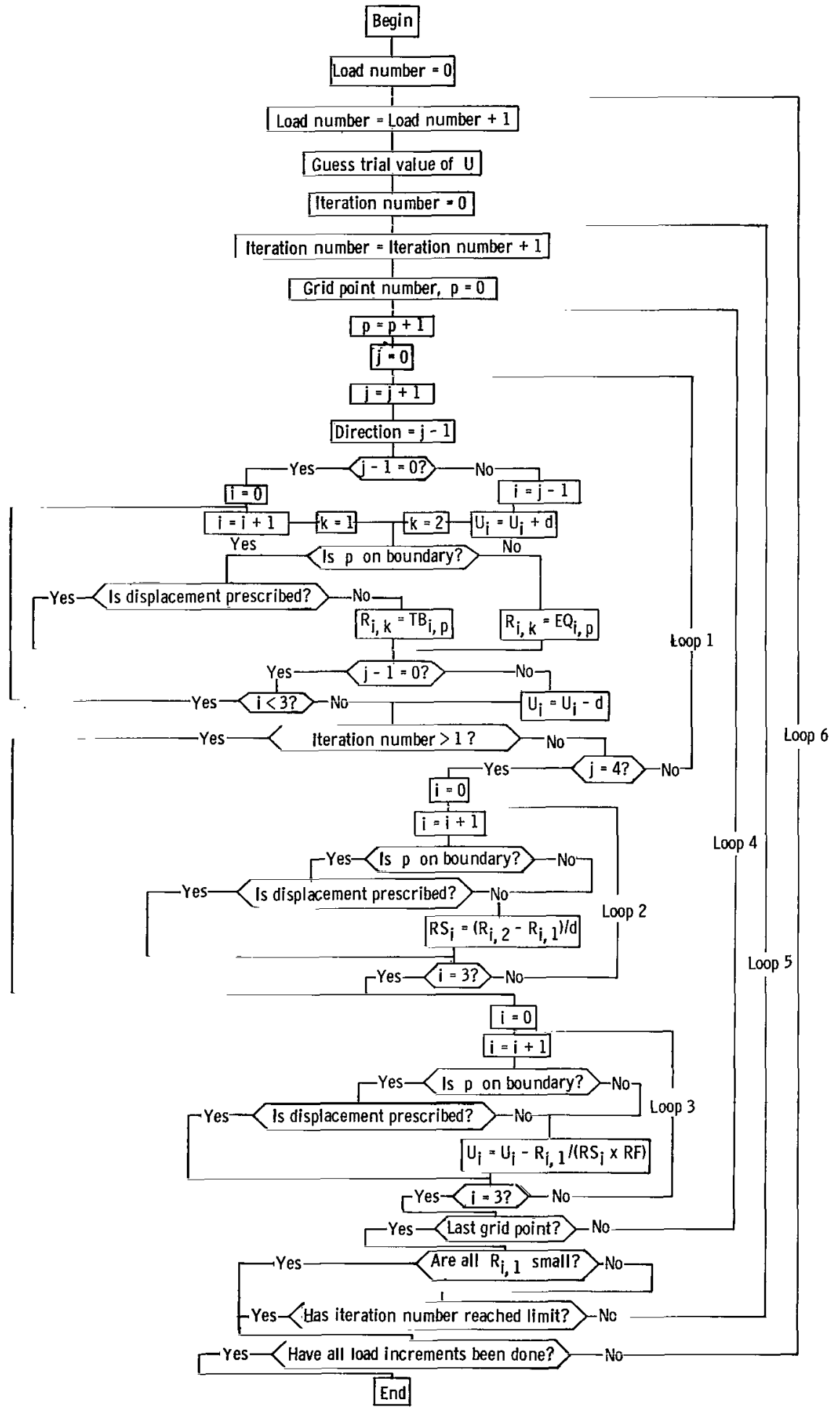

Figure 21. - Flow chart of numerical procedure. 


\section{REFERENCES}

1. Southwell, R. V.: Relaxation Methods in Engineering Science. Clarendon Press, Oxford, 1940.

2. Clough, Ray W.: The Finite Element Method in Structural Mechanics. Stress Analysis. O. C. Zienkiewicz and G. S. Holister, eds., John Wiley \& Sons, Inc., 1965, pp. 85-119.

3. Argyris, J. H. : Continua and Discontinua - An Apercu of Recent Developments of the Matrix Displacement Method. Presented at the Air Force Conference on Matrix Methods in Structural Mechanics, Wright-Patterson AFB, Ohio, Oct. 26-28, 1965.

4. Ang, A. H. S. ; and Harper, G. N.: Analysis of Contained Plastic Flow in Plane Solids. Proc. ASCE, J. Eng. Mech. Div., vol. 90, no. EM5, pt. 1, Oct. 1964, pp. $397-418$.

5. Mendelson, Alexander: Solutions of Some Plane Thermal and Crack Problems for Strain-Hardening Materials. PhD Thesis, Case Inst. Tech., 1965.

6. Ayres, David J.: A General Method for Computing Stress and Deformation in Soils. PhD Thesis, Carnegie-Mellon University, 1966.

7. Berezin, Ivan S.; and Zhidkov, N. P.: Computing Methods. Vol. 2. AddisonWesley Pub. Co., 1965.

8. Westergaard, H. M.: Bearing Pressures and Cracks. J. Appl. Mech., vol. 6, no. 2, June 1939, pp. 49-53.

9. Paris, Paul C.; and Sih, George C.: Stress Analysis of Cracks. Fracture Toughness Testing and Its Applications. Spec. Tech. Publ. No. 381, ASTM, 1965, pp. 30-83.

10. Green, A. E.: Three-Dimensional Stress Systems in Isotropic Plates. I. Phil. Trans. Roy. Soc., Ser. A, vol. 240, 1948, pp. 561-597.

11. Alblas, Johannes B.: Theory of the Three-Dimensional Stress State in a Plate with a Hole. Thesis submitted to Technical High School Delft, Netherlands, 1957. 